\title{
Postoperative Intestinal Fistula in Primary Advanced Ovarian Cancer Surgery
}

This article was published in the following Dove Press journal:

Cancer Management and Research

Antoni Llueca $\mathbb{D}^{1-3}$
Anna Serra $\mathbb{D}^{1-3}$
Maria Teresa Climent
Karina Maiocchi $\mathbb{D}^{2,4}$
Alvaro Villarin $\mathbb{D}^{2,4}$
Katty Delgado $\mathbb{D}^{2,5}$
Josep Mari-Alexandre $\mathbb{D}^{6}$
Juan Gilabert-Estelles $\mathbb{D}^{6,7}$
Paula Carrasco
Blanca Segarra $\mathbb{D}^{8}$
Luis Gomez $\mathbb{D}^{2,4}$
Juan Jose Hidalgo
Javier Escrig $\mathbb{D}^{3}$
Manuel Laguna $\mathbb{D}^{2,4}$
On behalf of the MUAPOS
working group $($ Multidisciplinary
Unit of Abdominal Pelvic
Oncology Surgery

'Department of Gynecology and Obstetrics, University General Hospital of Castellon, Castellón, Spain; ${ }^{2}$ Multidisciplinary Unit of Abdominal Pelvic Oncology Surgery (MUAPOS), University General Hospital of Castellon, Castellón, Spain; ${ }^{3}$ Department of Medicine, University Jaume I (UII), Castellon, Spain; ${ }^{4}$ Department of General Surgery, University General Hospital of Castellon, Castellón, Spain; ${ }^{5}$ Department of Radiology, University General Hospital of Castellon, Castellón, Spain; ${ }^{6}$ Research Laboratory in Biomarkers in Reproduction, Gynecology and Obstetrics, Fundación Hospital General Universitario de Valencia, Valencia, Spain; ${ }^{7}$ Department of Paediatrics, Obstetrics and Gynaecology, University of Valencia, Valencia, Spain; ${ }^{8}$ University of Texas MD Anderson Cancer Center, Gynecology Oncology, Houston, Texas, USA

Correspondence: Antoni Llueca Email antonillueca@gmail.com
Background: Advanced ovarian cancer (AOC) requires an aggressive surgery with large visceral resections in order to achieve an optimal or complete cytoreduction and increase the patient's survival. However, the surgical aggressiveness in the treatment of AOC is not exempt from major complications, such as the gastrointestinal fistula (GIF), which stands out among others due to its high morbidity and mortality.

Methods: We evaluated the clinicopathological features in patients with AOC and their association with GI. Data for 107 patients with AOC who underwent primary debulking surgery were analyzed retrospectively. Clinicopathological features, including demographic, surgical procedures and follow-up data, were analyzed in relation to GIF.

Results: GIF was present in $11 \%$ of patients in the study, $5(4.5 \%)$ and $7(6.4 \%)$ of colorectal and small bowel origin, respectively. GIF was significantly associated with peritoneal cancer index $(\mathrm{PCI})>20$, more than 2 visceral resections, and multiple digestive resections. Overall and disease-free survival were also associated with GIF. Multivariate analysis identified partial bowel obstruction and operative bleeding as independent prognostic factors for survival. The presence of GIF is positively associated with poor prognosis in patients with AOC.

Conclusion: Given the importance of successful cytoreductive surgery in AOC, the assessment of the amount of tumor and the aggressiveness of the surgery to avoid the occurrence of GIF become a priority in patients with AOC.

Keywords: advanced ovarian cancer surgery, complications, intestinal leakage, intestinal fistula

\section{Introduction}

According to the Spanish Society against Cancer (AECC), ovarian cancer is usually diagnosed between 45 and 75 years of age, and up to $75 \%$ of the cases are diagnosed in advanced stages, resulting in a poor prognosis. In 2016, there were approximately 3412 cases of ovarian cancer in Spain, 1960 of those case were lethal. ${ }^{1}$ However, the introduction of advanced ovarian cancer (AOC) surgery, which strives to achieve complete cytoreduction, aims to increase survival and provide a definitive cure in some cases. ${ }^{2}$ Such surgery is considered highly aggressive and often results in serious postoperative complications that could reach a rate of $38 \%$ reported in some systematic revisions and may cause an increase in patient mortality and the delay or impossibility of adjuvant oncological treatment. ${ }^{3}$ A multidisciplinary approach of AOC has been implemented by the Multidisciplinary Unit of Abdominal Pelvic Oncology Surgery (MUAPOS), at the General University Hospital in Castellon since 2013 and was able to increase the patients' survival in the past few years. ${ }^{4}$ An effort has been made in order 
to identify risk and prognostic factors retrospectively in patients who suffered complications, for instance, gastrointestinal fistulae, creating a predictive model for major complications after extensively primary debulking in order to predict morbidity. The study concluded that risk factors for major complications are: five or more visceral resections, rectosigmoid resection, glossectomy, and pelvic peritonectomy. ${ }^{5}$ We have currently taken a particular interest in the gastrointestinal fistulae (GIF), one of the most feared adverse events of extensive cytoreduction since rectosigmoid, jejunum and/or ileum resections are necessary for approximately $50 \%$ of the AOC surgeries. ${ }^{5}$ Some factors favor the occurrence of digestive fistula, in the immediate or late postoperative period, such as hydroelectric imbalance and malnutrition, in addition to the intestinal resection and/or neoadjuvant chemotherapy. This usually leads to aggressive treatments and prolonged hospitalizations. ${ }^{6-9}$

The objective of this study is twofold, to address the results concerning the GIF collected at the MUAPOS at the General University Hospital in Castellon, and to investigate the relationship with the survival of patients who experienced GIF.

\section{Patients and Methods}

Patients with stage IIIc and IV ovarian, peritoneal, and fallopian tube carcinoma who underwent primary cytoreduction, with intestinal resections (rectosigmoid, jejunum, ileum and/or colon), at the MUAPOS of the University General Hospital of Castellon in Spain from January 2013 to January 2018, were included. All of the patients had an Eastern Cooperative Oncology Group (ECOG) Score <3. Patients who were at risk of unresectability according to the advanced ovarian cancer management guide of the MUAPOS $^{10}$ received neoadjuvant chemotherapy and were excluded from this study. A prospective analytical study was carried out based on a retrospective analysis of the data.

Demographic, clinicopathological, and follow-up data were analyzed. Debulking status was defined: Complete (Group A): no residual; Optimal (Group B): residual tumor $<1 \mathrm{~cm}$; Suboptimal (Group C): residual tumor $>1 \mathrm{~cm}$. For this study, complications grade I-II and grade III-IV were categorized in Minor and Major, respectively, according to the Clavien-Dindo classification. ${ }^{11}$ When collecting data from complications, cancer-related procedures, ie diagnostic thoracentesis for staging, were not considered. For the diagnosis of malnutrition were used anthropometric, clinic and laboratory parameters. Mainly studied parameters were age, albumin prior to the intervention, peritoneal carcinomatosis index, chemotherapy administration and tumor staging.

GIF was defined as any exit of material from the digestive tract, which can remain in the abdominal cavity in the form of a collection (anastomosis leakage) or go outside either spontaneously or through a drain (true fistula). ${ }^{12}$ In the same way, GIF was categorized into the rectosigmoid anastomosis, related to colonic anastomosis, and related to small bowel anastomosis which includes genuine small bowel fistulae, gastro-jejunal, duodenal, and those related to anastomosis between the colon and small bowel.

The patients were staged following the International Federation of Obstetrics and Gynecology (FIGO) ${ }^{13}$ staging system, and the quantitative assessment of the carcinomatosis distribution was done following Sugabaker's Peritoneal Carcinomatosis Index (PCI) (categorized in $1-10,11-20,>20) .{ }^{14}$ The PCI was determined at the time of surgery by the same surgical team. Patients were informed of this study, and written informed consent was obtained from all the participants included in the study. The Ethics and Clinical Research Committee of the General University Hospital in Castellon also gave its approval. All procedures performed in this study were under the ethical standards of our Hospital and the 1964 Declaration of Helsinki.

\section{Statistical Analysis}

Statistical analysis was directed to compare two groups: Presence of GIF vs Absence of GIF. Means and Standard deviation were used for summarizing quantitative variables, counts and percentages for summarizing qualitative variables. For univariate statistics, the Mann-Whitney test was used to compare groups of quantitative nonparametric variables, and CHI-squared or Fisher's exact test to compare qualitative variables. As for the descriptive and univariate statistical analysis of overall and disease-free survival associated with the event of a GIF, Kaplan-Meier curves and Log Rank test were used. Medians and 95\% Confidence Intervals of survival were calculated. To identify the most influential independent factors in the appearance of GIF a multivariate analysis was performed with all significant and almost significant variables from the univariate analysis that has been included in a backwards-stepwise model of binary logistic regression, with the condition that those whose $p$ is less than 0.05 remain in the final model and more than 
Table I Clinicopathological Characteristics of All Patients

\begin{tabular}{|c|c|c|c|c|}
\hline & $\begin{array}{l}\text { Total } \\
n=107\end{array}$ & $\begin{array}{l}\text { No } \\
n=95 \text { (89\%) }\end{array}$ & $\begin{array}{l}\text { Yes } \\
n=\mid 2(1 \mid \%)\end{array}$ & $P$ value \\
\hline Age & $60 \pm 10.5$ & $60 \pm 10.6$ & $62 \pm 10.6$ & 0.52 \\
\hline FIGO stage & & & & 0.49 \\
\hline III & $80(74.8 \%)$ & $72(75.8 \%)$ & $8(66.7 \%)$ & \\
\hline IV & 27 (25.2\%) & $23(24.2 \%)$ & $4(33.3 \%)$ & \\
\hline Charlson & $2 \pm 2.2$ & $2 \pm 2.1$ & $3 \pm 2.4$ & 0.36 \\
\hline Charlson category & & & & 0.31 \\
\hline $\mathrm{CHRO}$ & $40(37.4 \%)$ & $36(37.9 \%)$ & $4(33.3 \%)$ & \\
\hline CHRI-3 & $33(30.8 \%)$ & 31 (32.6\%) & $2(16.7 \%)$ & \\
\hline CHR4-8 & $34(31.8 \%)$ & $28(29.5 \%)$ & $6(50 \%)$ & \\
\hline Preoperative malnutrition & & & & 0.090 \\
\hline No & $83(77.6 \%)$ & $76(80 \%)$ & 7 (58.3\%) & \\
\hline Yes & $24(22.4 \%)$ & $19(20 \%)$ & $5(41.7 \%)$ & \\
\hline Duration ( $\mathrm{min}$ ) of surgery & $440 \pm 163$ & $434 \pm 162.8$ & $490 \pm 162.2$ & 0.26 \\
\hline Operative $\mathrm{PCl}$ & $14 \pm 9.4$ & $13 \pm 9.1$ & $20 \pm 9.9$ & 0.027 \\
\hline Operative $\mathrm{PCl}$ category & & & & 0.14 \\
\hline $1-10$ & $43(41.7 \%)$ & 41 (45\%) & $2(16.7 \%)$ & \\
\hline $\mathrm{II}-20$ & $35(34.0 \%)$ & $30(33 \%)$ & $5(41.7 \%)$ & \\
\hline+20 & $25(24.3 \%)$ & $20(22 \%)$ & $5(41.7 \%)$ & \\
\hline Ascitis & & & & 0.98 \\
\hline NO & $80(74.8 \%)$ & $7 \mathrm{I}(74.7 \%)$ & $9(75 \%)$ & \\
\hline SI & $27(25.2 \%)$ & $24(25.3 \%)$ & $3(25 \%)$ & \\
\hline Partial bowel obstruction & & & & 0.017 \\
\hline No & $94(87.9 \%)$ & $86(90.5 \%)$ & $8(66.7 \%)$ & \\
\hline Yes & $13(12.1 \%)$ & $9(9.5 \%)$ & $4(33.3 \%)$ & \\
\hline Diffuse intestinal or mesos infiltration & & & & 0.25 \\
\hline No & $85(79.4 \%)$ & 77 (8I.1\%) & $8(66.7 \%)$ & \\
\hline Yes & $22(20.6 \%)$ & $18(18.9 \%)$ & $4(33.3 \%)$ & \\
\hline Major invasion of wall or retroperitoneum & & & & 0.44 \\
\hline No & $96(89.7 \%)$ & $86(90.5 \%)$ & $10(83.3 \%)$ & \\
\hline Yes & II (I0.3\%) & $9(9.5 \%)$ & $2(16.7 \%)$ & \\
\hline Tumor blocks or retractions & & & & 0.42 \\
\hline No & $89(83.2 \%)$ & $80(84.2 \%)$ & $9(75 \%)$ & \\
\hline Yes & $18(16.8 \%)$ & $15(15.8 \%)$ & $3(25 \%)$ & \\
\hline Diaphragmatic invasion & & & & 0.81 \\
\hline No & $96(89.7 \%)$ & 85 (89.5\%) & II (91.7\%) & \\
\hline Yes & $\mathrm{II}(\mathrm{I} 0.3 \%)$ & $10(10.5 \%)$ & I (8.3\%) & \\
\hline
\end{tabular}

0.15 are removed. A Network analysis using JASP software . JASP (Version 0.13.1) URL $=$ \{https://jasp-stats. org/ $\}$ was performed with the most significant risk factors $(p<0.15)$ for GIF in the multivariate analysis to show the strength of their correlations. The remaining analysis of statistical data was performed using the IBM-SPSS software version 25 (IBM Corp. Released 2017. IBM SPSS Statistics for Windows, Version 25.0. Armonk, NY: IBM Corp.). A p-value $<0.05$ was considered statistically significant. 
Table 2 Principal Procedures Concerning GIF

\begin{tabular}{|c|c|c|c|c|}
\hline & $\begin{array}{l}\text { Total } \\
\mathrm{N}=107\end{array}$ & $\begin{array}{l}\text { GIF No } \\
\text { N=95 (89\%) }\end{array}$ & $\begin{array}{l}\text { GIF Yes } \\
N=12(1 \mid \%)\end{array}$ & $P$ value \\
\hline Peritonectomy & & & & 0.06 \\
\hline No & $24(22.4 \%)$ & $22(92 \%)$ & $2(8 \%)$ & \\
\hline Complete & 31 (29\%) & $24(77 \%)$ & $7(23 \%)$ & \\
\hline Partial & $52(48.6 \%)$ & $49(94 \%)$ & $3(6 \%)$ & \\
\hline Fulguration or excision of nodules & & & & 0.39 \\
\hline No & $57(53.3 \%)$ & $52(91 \%)$ & $5(9 \%)$ & \\
\hline Yes & $50(46.7 \%)$ & $43(86 \%)$ & $7(14 \%)$ & \\
\hline Visceral resection & & & & 0.85 \\
\hline No & $20(18.7 \%)$ & $18(90 \%)$ & $2(10 \%)$ & \\
\hline Yes & $87(81.3 \%)$ & $77(89 \%)$ & $10(11 \%)$ & \\
\hline Bowel resection & & & & 0.56 \\
\hline No & $25(23.4 \%)$ & $23(92 \%)$ & $2(8 \%)$ & \\
\hline Yes & $82(76.6 \%)$ & $72(88 \%)$ & $10(12 \%)$ & \\
\hline Type of bowel resection & & & & 0.13 \\
\hline No & $25(23.4 \%)$ & $23(92 \%)$ & $2(8 \%)$ & \\
\hline Rectum-Sigmoid & $15(14.0 \%)$ & $15(100 \%)$ & 0 & \\
\hline Colon & $20(18.7 \%)$ & 19 (95\%) & I (5\%) & \\
\hline Small bowel & $22(20.6 \%)$ & $19(86 \%)$ & $3(14 \%)$ & \\
\hline Multiple & $25(23.4 \%)$ & $19(76 \%)$ & $6(24 \%)$ & \\
\hline Pancreas and/or spleen resection & & & & 0.86 \\
\hline No & 78 (72.9\%) & $69(89 \%)$ & $9(11 \%)$ & \\
\hline Yes & $29(27.1 \%)$ & $26(90 \%)$ & $3(10 \%)$ & \\
\hline Number of visceral resections & $4 \pm 3.1$ & $3 \pm 2.8$ & $6 \pm 4.1$ & $<0.001$ \\
\hline Grouped number of visceral resections & & & & 0.07 \\
\hline $0-2$ & $44(41.1 \%)$ & $42(96 \%)$ & $2(4 \%)$ & \\
\hline$>2$ & $63(58.9 \%)$ & $53(84 \%)$ & $10(16 \%)$ & \\
\hline Digestive anastomosis & & & & 0.06 \\
\hline No & $45(42.1 \%)$ & $43(96 \%)$ & $2(4 \%)$ & \\
\hline Yes & $62(57.9 \%)$ & $52(84 \%)$ & $10(16 \%)$ & \\
\hline Mean digestive anastomosis per patient & $0.9 \pm 0.1$ & $0.8 \pm 0.1$ & $1.3 \pm 0.3$ & 0.13 \\
\hline Grouped number of digestive anastomosis per patient & & & & 0.20 \\
\hline $0-1$ & $86(80.4 \%)$ & $78(91 \%)$ & $8(9 \%)$ & \\
\hline$>1$ & $21(19.6 \%)$ & $17(81 \%)$ & $4(19 \%)$ & \\
\hline Definitive stoma & & & & 0.99 \\
\hline No & $89(83.2 \%)$ & $79(89 \%)$ & $10(11 \%)$ & \\
\hline Yes & $18(16.8 \%)$ & $16(89 \%)$ & $2(11 \%)$ & \\
\hline Lymphadenectomy & & & & 0.76 \\
\hline No & $49(45.8 \%)$ & $43(88 \%)$ & $6(12 \%)$ & \\
\hline Yes & $58(54.2 \%)$ & $52(90 \%)$ & $6(10 \%)$ & \\
\hline Operative bleeding cc & $1926 \pm 887$ & $1856 \pm 893$ & $2483 \pm 611$ & 0.02 \\
\hline Grouped operative bleeding cc & & & & 0.01 \\
\hline $0-1000$ & $17(15.9 \%)$ & $17(100 \%)$ & 0 & \\
\hline $1000-2000$ & $57(53.3 \%)$ & $53(93 \%)$ & $4(7 \%)$ & \\
\hline $2000-3000$ & 24 (22.4\%) & $17(71 \%)$ & 7 (29\%) & \\
\hline+3000 & $9(8.4 \%)$ & $8(89 \%)$ & I (II\%) & \\
\hline
\end{tabular}

(Continued) 
Table 2 (Continued).

\begin{tabular}{|c|c|c|c|c|}
\hline & $\begin{array}{l}\text { Total } \\
N=107\end{array}$ & $\begin{array}{l}\text { GIF No } \\
\text { N=95 (89\%) }\end{array}$ & $\begin{array}{l}\text { GIF Yes } \\
N=12 \text { (11\%) }\end{array}$ & $P$ value \\
\hline Cytoreduction & & & & 0.83 \\
\hline Group A & $84(78.5 \%)$ & $74(88 \%)$ & $10(12 \%)$ & \\
\hline Group B & $8(7.5 \%)$ & $7(88 \%)$ & $\mathrm{I}(12 \%)$ & \\
\hline Group C & $15(14 \%)$ & $14(93 \%)$ & I (7\%) & \\
\hline Cytoreduction & & & & 0.54 \\
\hline Group A + B & $92(86 \%)$ & $81(88 \%)$ & II (12\%) & \\
\hline Group C & $15(14 \%)$ & $14(93 \%)$ & I (7\%) & \\
\hline Length of stay & $22 \pm 20.7$ & $19 \pm 14.6$ & $49 \pm 38.1$ & $<0.001$ \\
\hline Grade CLAVIEN-DINDO & & & & $<0.001$ \\
\hline No complication & $50(46.7 \%)$ & $50(100 \%)$ & 0 & \\
\hline 1 & II (I0.3\%) & II (100\%) & 0 & \\
\hline II & $13(12.1 \%)$ & $13(100 \%)$ & 0 & \\
\hline III & $27(25.2 \%)$ & $17(63 \%)$ & $10(37 \%)$ & \\
\hline IV & $6(5.7 \%)$ & $4(67 \%)$ & $2(33 \%)$ & \\
\hline Complication grade & & & & $<0.001$ \\
\hline No complication & $50(46.7 \%)$ & $52(100 \%)$ & 0 & \\
\hline Minor (I-II) & 24 (22.4\%) & $24(100 \%)$ & 0 & \\
\hline Major (III-IV) & $33(30.9 \%)$ & $19(58 \%)$ & $12(42 \%)$ & \\
\hline Radiologically or endoscopically intervention & & & & $<0.001$ \\
\hline No & $89(83.2 \%)$ & $84(94 \%)$ & $5(6 \%)$ & \\
\hline Yes & $18(16.8 \%)$ & $11(61 \%)$ & $7(39 \%)$ & \\
\hline Surgical reintervention & & & & $<0.001$ \\
\hline No & $90(84.1 \%)$ & $86(96 \%)$ & $4(4 \%)$ & \\
\hline Yes & $17(15.9 \%)$ & $9(53 \%)$ & $8(47 \%)$ & \\
\hline 90 days mortality & & & & 0.002 \\
\hline No & $103(96,3 \%)$ & $92(91 \%)$ & $9(9 \%)$ & \\
\hline Yes & $4(3,7 \%)$ & $3(50 \%)$ & $3(50 \%)$ & \\
\hline Disease recurrence & & & & 0.95 \\
\hline No & $49(45.8 \%)$ & $38(78 \%)$ & $5(22 \%)$ & \\
\hline Yes & 58 (54.2\%) & $51(88 \%)$ & $7(12 \%)$ & \\
\hline Type of disease recurrence & & & & 0.88 \\
\hline Peritoneal & $16(27.6 \%)$ & $14(88 \%)$ & $2(12 \%)$ & \\
\hline Metastases & 31 (53.4\%) & $27(87 \%)$ & $4(13 \%)$ & \\
\hline Both & II (19\%) & $9(82 \%)$ & $2(18 \%)$ & \\
\hline
\end{tabular}

\section{Results}

During the study period, 107 patients met the inclusion criteria. Given the preexisting interest to study prognostic factors related to GIF, the patients were divided into two groups: those who did not present this type of complication (95 patients) and those that did present it (12 patients), meaning that $11 \%$ of the patients in the study suffered from a GIF, $5(4.5 \%)$ and $7(6.4 \%)$ of colorectal and small bowel origin, respectively. Of the 12 GIF patients, 4 patients were true fistulas and 8 anastomosis leakage.
Table 1 summarizes the clinicopathologic characteristics of patients. Table 2 summarizes the characteristics of the surgery and outcomes.

The average age in the group of GIF was 62 years, compared to the 60 years in the other group. Concerning the average duration of surgery, in the group of GIF, it was 510 minutes, compared to the 450 minutes in the other group. GIF incidence was higher $(31 \%)$ in the presence of partial bowel obstruction than in its absence $(8 \%)$. Logically, the percentage of bowel resections in GIF was 
Table 3 The Final Model of Backward-Stepwise Logistic Regression Based on the Variables Associated with Univariate Incidence Risk of GIF

\begin{tabular}{|l|l|l|l|}
\hline GIF & Odds Ratio & Cl 95\% & P value \\
\hline Operative bleeding $(\mathrm{mL})$ & 1.01 & $1.001-1.022$ & 0.016 \\
Partial bowel obstruction & 6.26 & $1.406-27.671$ & 0.015 \\
\hline
\end{tabular}

$12 \%$, compared to those who did not, which was $8 \%$. A total operative PCI mean of 20 was higher in the GIF group, while the group that did not present the complication had a mean of 13 . Eighty-three patients (78\%) did not receive any kind of nutritional support, while $24(22 \%)$ received nutritional supplements and/or parenteral nutrition. GIF incidence was higher $(21 \%)$ in the presence of preoperative malnutrition than in its absence $(8 \%)$.

Principal procedures with anastomotic leakage are shown in Table 2. GIF had a higher incidence (23\%) when complete peritonectomy was performed than when not $(8 \%)$ performed. Multiple intestinal resections were done in the majority of cases of GIF, and the number of visceral resections was more than 2 in the $16 \%$ of patients with GIF. When blood loss was higher than $2000 \mathrm{~mL}$, it was associated with GIF in $29 \%$ of patients. The type of cytoreduction was not associated with the rate of GIF. However, there was more incidence of GIF when complete or optimal cytoreduction (group A+B) (12\%) was performed than when it was suboptimal (group C) (7\%). No fistula was observed when only a colorectal anastomosis was performed. In exclusively colonic anastomoses, we found 1 (5\%) fistula, compared to $3(14 \%)$ in only small bowel anastomosis, and 6 (24\%) when multiple colorectal and small bowel anastomoses were performed. No protective stoma was performed.

The number of GIF with or without definitive stoma was identical (11\%). Significant complications were found in $33(31 \%)$ patients, $19(58 \%)$ and $12(42 \%)$ without and with GIF. Finally, about the surgical reoperation, it was required in $17(16 \%)$ patients, $8(47 \%)$ of those presenting a GIF. In those who did not require reoperation, only 4 (4\%) presented GIF.

Multivariate analysis (Table 3) revealed that partial bowel obstruction and operative bleeding are the only independent risk factors for the appearance of GIF.

Network analysis was performed with the most significant risk factors $(p<0.15)$ in the multivariate analysis to show the strength of their correlation. The matrix of weights correlations and paths are shown in Table 4 and Figure 1.

Cumulative survival analysis using Kaplan-Meier curves in the presence or absence of a GIF is shown in Figure 2 and Table 5. Median survival was 16 months (95\% CI 0-35.3) and 37.63 months (95\% CI: 29.7-45.4) in patients with and without GIF. Median disease-free interval in months (Figure 3) was12 (95\% CI: 3.8-20.1) and19.6 (95\% CI: 9.5-29.6). Kaplan-Meier survival curves were also constructed, specifying the type of fistula (Figure 4). Cumulative survival for Colorectal and small bowel fistula and absence of GIF were 16, 6.5 and 37.6 months, respectively. The disease-free interval for the different types of GIF was 19.6 months (95\% CI: 9.5-29.6) for the absence of GIF and 12 (95\% CI: $0-36.5)$ and 5.8 (95\% CI: 3.0-8.5) for Colorectal and Small bowel fistulas, respectively (Figure 5).

\section{Discussion}

In this study, partial bowel obstruction and Operative bleeding are the most important predictive factors in the appearance of GI fistulas in advanced ovarian cancer surgery.

In most studies on peritoneal carcinomatosis originating from ovarian cancer, it has been observed that the

Table 4 Network Weights Matrix of Correlations

\begin{tabular}{|l|l|l|l|l|l|}
\hline & Charlson & Fistula & PCI & Bleeding & Obstruction \\
\hline Charlson & - & 0.141 & -0.067 & -0.163 & 0.137 \\
Fistula & 0.141 & - & 0.322 & 0.374 & 0.457 \\
PCl & -0.067 & 0.322 & - & 0.221 & 0.269 \\
Bleeding & -0.163 & 0.374 & 0.221 & - & -0.039 \\
Obstruction & 0.137 & 0.457 & 0.269 & -0.039 & - \\
\hline
\end{tabular}




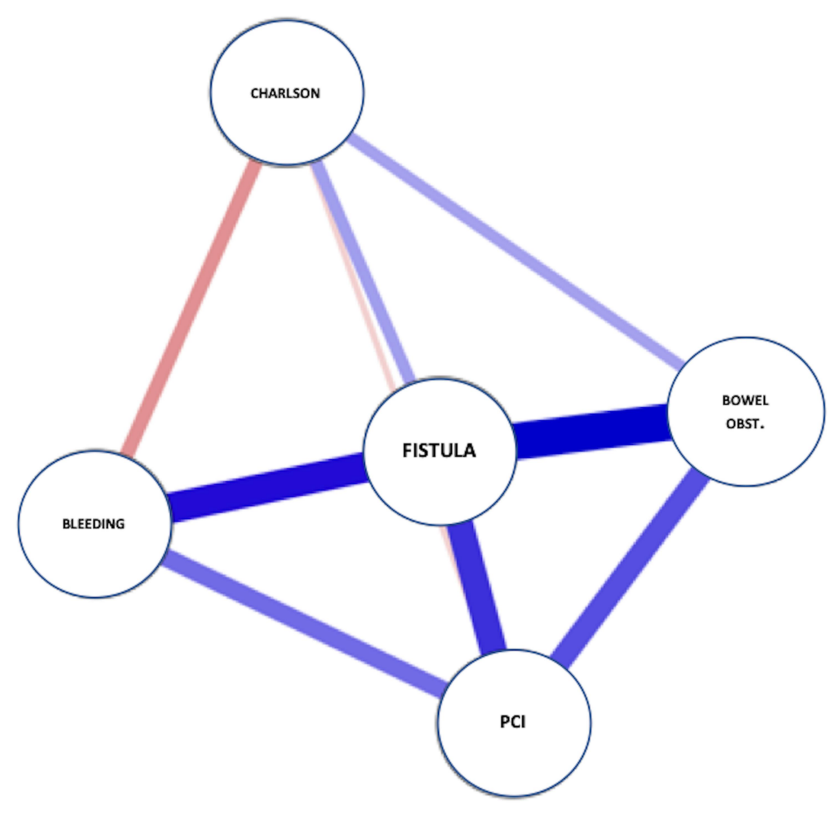

Figure I Network paths of correlations.

complete or optimal cytoreduction and platinum-based chemotherapy are the only factors that are clearly associated with a better survival rate in these patients. ${ }^{4}$ According to our MUAPOS database, $86 \%$ of our patients benefitted from an optimal cytoreduction (Group $\mathrm{A}+\mathrm{B}$ ), $11 \%$ of those developed a gastrointestinal fistula.

Now it is time to distinguish anastomosis leakage from fistula in digestive surgery:
Fistula and leaks are terms, which are often used interchangeably. However, technically, they are somewhat different as we stated in the method section. ${ }^{12}$ These terms are usually employed in the same clinical situations, but their repercussion in terms of morbidity is not the same. While anastomosis leakage can be resolved frequently with radiological intervention, GIF frequently requires a surgical approach and the clinical repercussion is worse for the patient. These different definitions are not usually recorded in the literature. ${ }^{12}$

There is significant variability of GIF/leakages rates in the literature which can range from $4 \%$ to $20 \%{ }^{15}$ In our data, half of the anastomotic leaks were treated by interventional radiology so they could be considered anastomosis leakage instead of real fistulas. Moreover, no GIF fistulas were observed in cases of simple colorectal resections. Like other authors, we have stated that GIF of colorectal origin is more frequent in cases of multiple bowel resections. ${ }^{16}$

The different types of GIF are more frequently associated with two or more visceral resections as we can see in our data. As previously described, ${ }^{17,18}$ the tumor burden affects the number of resections performed in patients with advanced ovarian cancer so that with a high tumor load, quantified as a PCI $>20$, more than 3 resections would be performed to achieve optimal cytoreduction.

Survival in patients with fistula decreases compared to patients without it; surely this is because the hospital stay is

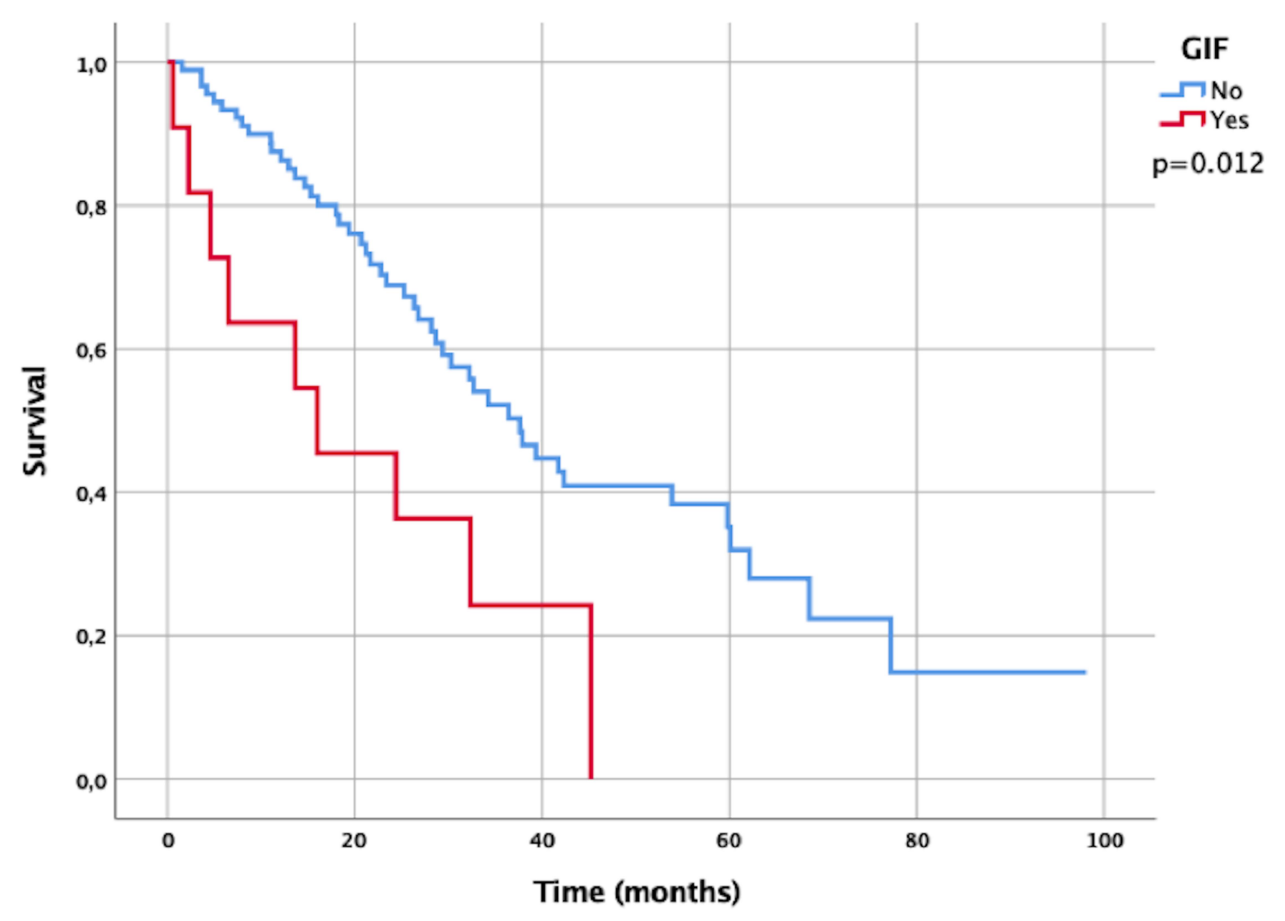

Figure 2 Overall survival according to the existence or absence of GIF. 
Table 5 Median Survival in Months in Patients with or Without GIF

\begin{tabular}{|l|l|l|l|l|}
\hline & $\begin{array}{l}\text { Median } \\
\text { Survival } \\
\text { (Months) }\end{array}$ & $\begin{array}{l}\text { Median } \\
\text { Cl 95\% }\end{array}$ & $\begin{array}{l}\text { Hazard Ratio } \\
\text { (GIF vs No } \\
\text { GIF) }\end{array}$ & $\begin{array}{l}\text { Hazard } \\
\text { Ratio Cl } \\
\mathbf{9 5 \%}\end{array}$ \\
\hline $\begin{array}{l}\text { GIF } \\
\text { No GIF }\end{array}$ & 16 & $4.6-45.2$ & 2.4 & $1.33-10.02$ \\
Global & 34 & $28.6-59.8$ & & \\
\hline
\end{tabular}

prolonged and causes patients not to start or to delay the onset of chemotherapy and this impacts negatively in survival. ${ }^{6-8,16}$ Moreover, survival among different types of GIFs is different. We observe that survival is worse in cases of small bowel fistulas. This negative impact on survival is probably caused by the impact on the general condition of the patient, in the form of dehydration and renal failure, which is frequently associated with this type of fistula. ${ }^{19,20}$

It has been described that malnutrition status is a risk factor for anastomosis leakage in ovarian cancer surgery. ${ }^{21}$ In our results, five patients $(21 \%)$ with GIF had malnutrition status at the time of surgery.

The network analysis represents either symmetric relations or asymmetric relations between the variables that influence the appearance of GIF. ${ }^{22}$ As we can see in the graph, there is a strong correlation between bowel obstruction, bleeding, and
PCI with the appearance of GIF. It is well known that with a high tumor burden quantified as a high PCI number, the risk of bowel obstruction increases, and the bleeding produced during surgery is higher. ${ }^{17,18,23-25}$ Multivariate analysis revealed that partial bowel obstruction increases six times the risk of postoperative digestive fistula, along with an increase of operative bleeding. Both variables were the only independent risk factors in our study, and they were both surrogates variables of the tumor burden and the extent of surgery. It is well known that the state of intestinal occlusion or suboclusion could generate an inflammatory environment in the intestinal wall and therefore more prone to fistulization; in this situation, any suture in this area may heal worse.

Strengths of this study include the homogeneous cohort of patients, in a tertiary hospital with a uniform approach to the treatment of AOC, making it relevant for those at highest risk for GIF. One of our main limitations here is the retrospective design and analysis of the data, which difficult the reproduction in other environments.

\section{Conclusions}

The digestive fistula in the postoperative period derives from multiple risk factors. In other words, it is multifactorial. Specifically, in this study, some factors have more weight than others, such as intraoperative bleeding and the presence of partial bowel obstruction. But in Table 4 it can be seen that

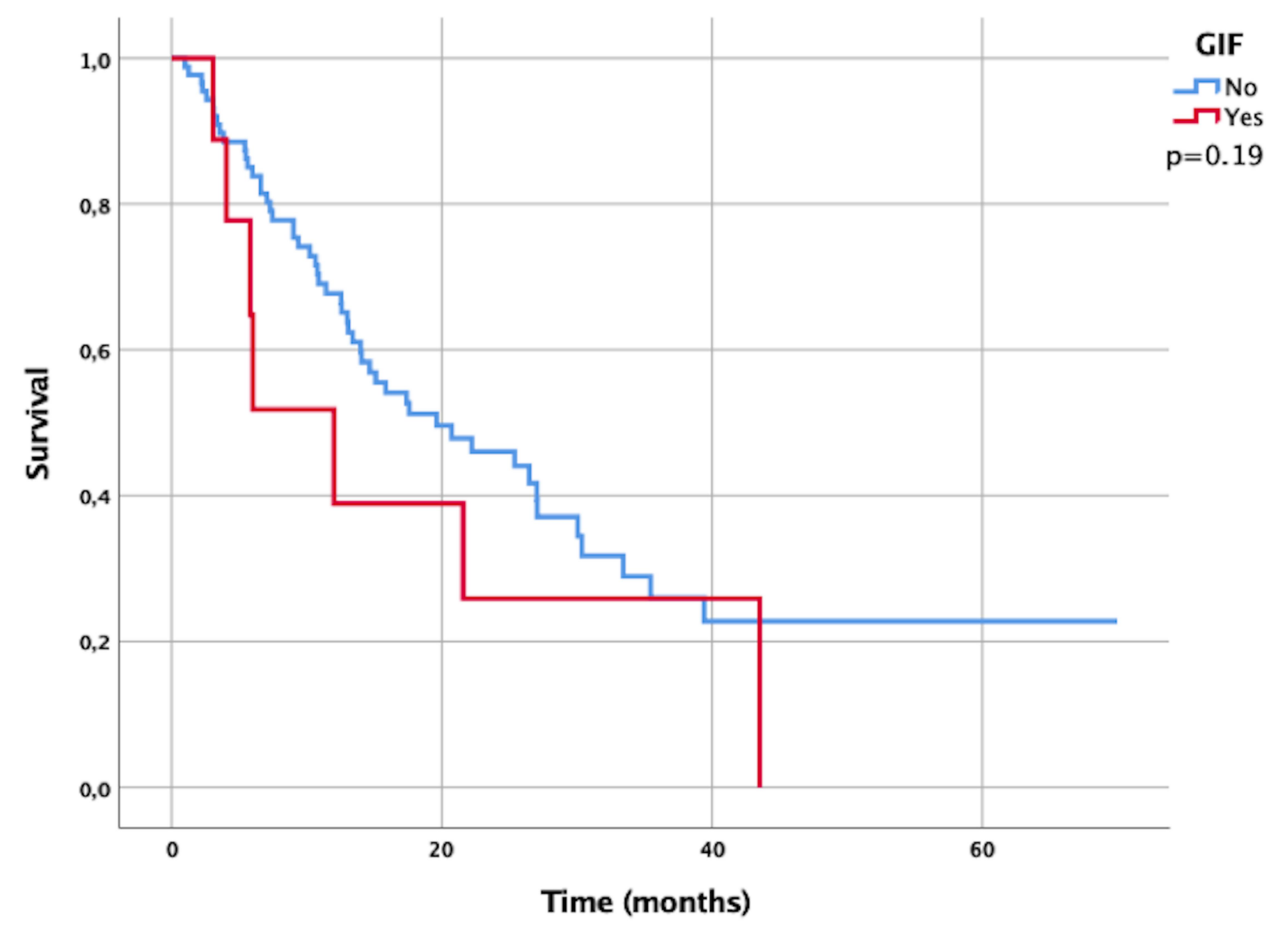

Figure 3 Disease-free survival according to the existence or absence of GIF. 


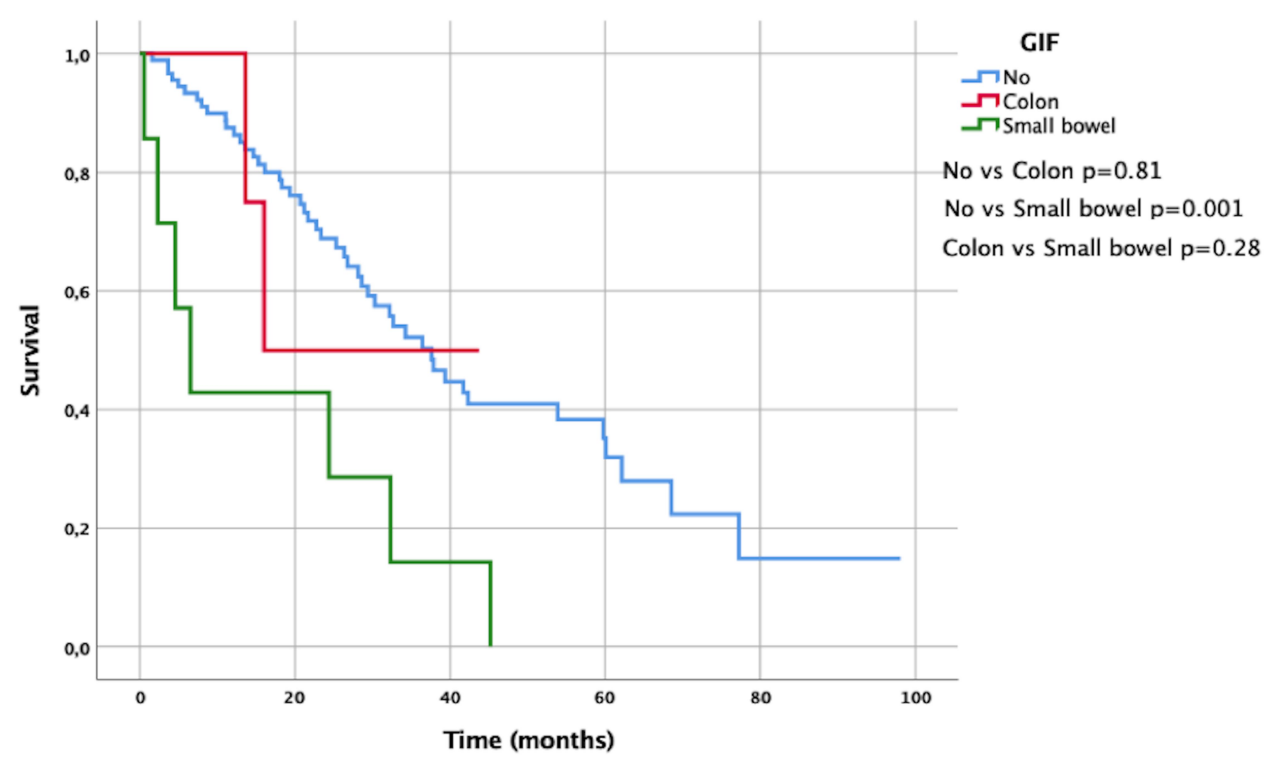

Figure 4 Overall survival for different types of GIF.

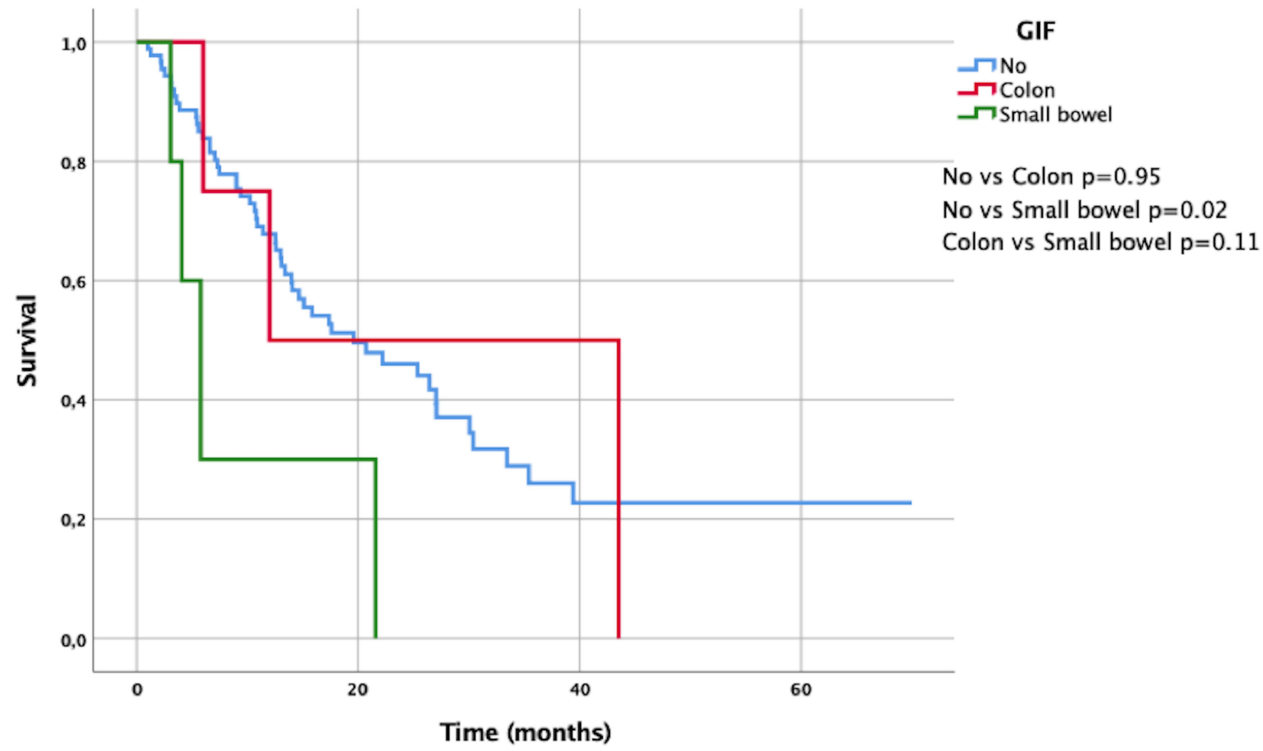

Figure 5 Disease-free survival for different types of GIF.

there are other risk factors that are highly correlated with fistulas, such as the extent of the disease itself (PCI), and comorbidity, and very strikingly, that there are crosscorrelations (covariance) between them. A maximum effort to achieve a complete cytoreduction in a context of a lot of peritoneal diseases and in a debilitated patient will suppose a highly aggressive surgery that will carry the highest risk of postoperative complications, including fistulas and probably they, therefore, jeopardize further treatment.

Assuming correct execution of the surgical technique, the best prevention of fistula (and other complications) can only consist of planning the intervention aimed at achieving the maximum cytoreduction possible with the least possible surgical aggression. Probably, combining both things depends to a very high degree on the technical training and experience of the surgical team.

\section{Data Sharing Statement}

The data that support the findings of this study are available from the corresponding author upon reasonable request. 


\section{Acknowledgments}

We thank Begoña Belles, $\mathrm{PhD}$, for editing a draft of this manuscript.

MUAPOS working group (Multidisciplinary Unit of Abdominal Pelvic Oncology Surgery):

Gomez-Quiles L., Játiva R., Cebrian G., Bosso, V., Villarin, A., Maiocchi, K., Delgado-Barriga K., RodrigoAliaga M., Ruiz N., Herrero C., Frances, A., Beato I, Ferrer C., Aracil JP, Boldo E, Boldo A, Adell R.

\section{Funding}

This work received financial support from de Medtronic University Chair for Training and Surgical Research, University Jaume I (UJI), Castellón, Spain and also supported by a research grant from ISCIII-FEDER (PI17/ 01945).

\section{Disclosure}

The authors report no conflicts of interest in this work.

\section{References}

1. Sociedad Española de Oncología Médica (SEOM). Full-Text. Las cifras del cáncer en España 2018 [Internet]; 2018. 24. Available from: https://seom.org/seomcms/images/stories/recursos/Las_Cifras_ del_cancer_en_Espana2018.pdf. Accessed December 17, 2020.

2. Du Bois A, Reuss A, Pujade-Lauraine E. Role of surgical outcome as prognostic factor in advanced epithelial ovarian cancer: a combined exploratory analysis of 3 prospectively randomized Phase 3 multicenter trials: by the Arbeitsgemeinschaft Gynaekologische Onkologie Studiengruppe Ovarialkarzinom (AGO-OVAR) and the Groupe d'Investigateurs Nationaux Pour les Etudes des Cancers de l'Ovaire (GINECO). Cancer. 2009;115(6):1234. doi:10.1002/cncr.24149

3. Bartels HC, Rogers AC, Postle J, et al. Morbidity and mortality in women with advanced ovarian cancer who underwent primary cytoreductive surgery compared to cytoreductive surgery for recurrent disease: a meta-analysis. Pleura Peritoneum. 2019;4(2):20190014. doi:10.1515/pp-2019-0014

4. Llueca A, Herraiz JL, Catala C. Effectiveness and safety of cytoreduction surgery in advanced ovarian cancer: initial experience at a University General Hospital. J Clin Gynecol Obstetrics. 2015;4 (3):251-257. doi: $10.14740 /$ jcgo345w

5. Llueca A, Serra A, Maiocchi K, et al. Predictive model for major complications after extensive abdominal surgery in primary advanced ovarian cancer. Int J Women's Health. 2019;11:161-167. doi:10.2147/ IJWH.S190493

6. Hoffman MS, Zervose E. Colon resection for ovarian cancer: intraoperative decisions. Gynecol Oncol. 2008;111(2):S 56-65. doi:10.1016/ j.ygyno.2008.07.055

7. Tebes SJ, Cardosi R, Hoffman MS. Colorectal resection in patients with ovarian and primary peritoneal carcinoma. Am J Obstet Gynecol. 2006;195(2):585-589. doi:10.1016/j.ajog.2006.03.079

8. Bristow RE, Peiretti M, Gerardi M, et al. Secondary cytoreductive surgery including rectosigmoid colectomy for recurrent ovarian cancer: operative technique and clinical outcome. Gynecol Oncol. 2009;114(2):173-177. doi:10.1016/j.ygyno.2009.05.004
9. Kato K, Nomura H, Nagashima M, Takeshima N. Secondary debulking surgery for isolated pelvic nodal recurrence requiring external iliac vein excision and reconstruction in a patient with ovarian cancer. Gynecol Oncol. 2016;143(3):684-685. doi:10.1016/j.ygyno.2016.09.008

10. Llueca A, Serra-Rubert A, Escrig J. MUAPOS working group (Multidisciplinary Unit of Abdominal Pelvic Oncology Surgery). Prognostic value of peritoneal cancer index in primary advanced ovarian cancer. Eur J Surg Oncol. 2018;44:163-169. doi:10.1016/j. ejso.2017.11.003

11. Clavien PA, Sanabria JR, Strasberg SM. Proposed classification of complications of surgery with examples of utility in cholecystectomy. Surgery. 1992;111:518-526.

12. Goenka MK, Goenka U. Endotherapy of leaks and fistula. World J Gastrointest Endosc. 2015;7(7):702-713. doi:10.4253/wjge.v7.i7.702

13. Prat J. FIGO Committee on Gynecologic Oncology. Staging Classification for cancer of the Ovary, Fallopian tube, and peritoneum. Int J Gynecol Obstet. 2014;124:1-5. doi:10.1016/j.ijgo.2013.10.001

14. Sugarbaker PH, Jablonski KA. Prognostic features of 51 colorectal and 130 appendiceal cancer patients with peritoneal carcinomatosis treated by cytoreductive surgery and intraperitoneal chemotherapy. Ann Surg. 1995;221(2):124-132. doi:10.1097/00000658-199502000-00002

15. Koscielny A, Ko A, Egger E, Kuhn W, Kalff JC, Keyver-Paik MD. Prevention of anastomotic leakage in ovarian cancer debulking surgery and Its impact on overall survival. Anticancer Res. 2019;39(9):5209-5218.

16. Kalogera E, Dowdy SC, Mariani A, et al. Multiple large bowel resections: potential risk factor for anastomotic leak. Gynecol Oncol. 2013;130(1):213-218. doi:10.1016/j.ygyno.2013.04.002

17. Bartl T, Schwameis R, Stift A, et al. Predictive and prognostic implication of bowel resections during primary cytoreductive surgery in advanced epithelial ovarian cancer. Int J Gynecol Cancer. 2018;28 (9):1664-1671. doi:10.1097/IGC.0000000000001369

18. Llueca A, Serra A, Rivadulla I, Gomez L, Escrig J. MUAPOS working group (multidisciplinary unit of abdominal pelvic oncology surgery). Prediction of suboptimal cytoreductive surgery in patients with advanced ovarian cancer based on preoperative and intraoperative determination of the peritoneal carcinomatosis index. World J Surg Oncol. 2018;16:37. doi:10.1186/s12957-018-1339-0

19. Glasgow MA, Shields K, Vogel RI, Teoh D, Argenta PA. Postoperative readmissions following ileostomy formation among patients with a gynecologic malignancy. Gynecol Oncol. 2014;134 (3):561-565. doi:10.1016/j.ygyno.2014.06.005

20. Richardson DL, Mariani A, Cliby WA. Risk factors for anastomotic leak after recto-sigmoid resection for ovarian cancer. Gynecol Oncol. 2006;103(2):667-672. doi:10.1016/j.ygyno.2006.05.003

21. Garcia Martínez T, Montanes Pauls B, Vicedo Cabrera A, et al. Evaluacion y soporte nutricional en pacientes con carcinomatosis peritoneal por cáncer de ovario con citorreducción quiruúrgica. Nutr Cli'n Diet Hosp. 2016;36(1):31-40.

22. Oldham MC, Langfelder P, Horvath S. Network methods for describing sample relationships in genomic datasets: application to Huntington's disease. BMC Syst Biol. 2012;6(63). doi:10.1186/ 1752-0509-6-63.

23. Grimm C, Harter P, Alesina PF, et al. The impact of type and number of bowel resections on anastomotic leakage risk in advanced ovarian cancer surgery. Gynecol Oncol. 2017;146(3):498-503. doi:10.1016/j. ygyno.2017.06.007

24. Gallotta V, Fanfani F, Vizzielli G. Douglas peritonectomy compared to recto-sigmoid resection in optimally cytoreduced advanced ovarian cancer patients: analysis of morbidity and oncological outcome. Eur J Surg Oncol. 2011;37(12):1085-1092. doi:10.1016/j.ejso.2011.09.003

25. Gallotta V, Fanfani F, Fagotti A. Mesenteric lymph node involvement in advanced ovarian cancer patients undergoing rectosigmoid resection: prognostic role and clinical considerations. Ann Surg Oncol. 2014;21(7):2369-2375. doi:10.1245/s10434-014-3558-0 


\section{Publish your work in this journal}

Cancer Management and Research is an international, peer-reviewed open access journal focusing on cancer research and the optimal use of preventative and integrated treatment interventions to achieve improved outcomes, enhanced survival and quality of life for the cancer patient.

Submit your manuscript here: https://www.dovepress.com/cancer-management-and-research-journa
The manuscript management system is completely online and includes a very quick and fair peer-review system, which is all easy to use. Visit http://www.dovepress.com/testimonials.php to read real quotes from published authors. 